\title{
Microbial activity inhibition in chilled mackerel (Scomber scombrus) by employment of an organic acid-icing system
}
Minia Sanjuás-Rey ${ }^{1}$, José M. Gallardo ${ }^{2}$, Jorge Barros-Velázquez ${ }^{1}$, Santiago P. Aubourg ${ }^{2, *}$

${ }^{1}$ Department of Analytical Chemistry, Nutrition and Food Science, School of Veterinary Sciences, University of Santiago de Compostela, Lugo, Spain.

${ }^{2}$ Department of Food Technology. Marine Research Institute (CSIC), Vigo, Spain.

* Correspondent: saubourg@iim.csic.es; + 34986231930 (phone); + 34 986292762 (fax). 
The present work concerns Atlantic mackerel (Scomber scombrus) traded as a

31 chilled product. The study was aimed to investigate the effect of including a mixture of

32 organic acids (citric, ascorbic and lactic) in the icing medium employed during the fish

33 chilled storage. To this end and according to preliminary trials results, an aqueous

34 solution including $0.050 \%(\mathrm{w} / \mathrm{v})$ of each acid was employed as icing medium; its effect on the microbial activity development in mackerel muscle was monitored for up to 13 days of chilled storage and compared to a counterpart-fish batch kept under traditional water ice considered as control. Results indicated a lower bacterial growth in mackerel muscle subjected to storage in the organic acid-icing system by comparison with control fish. Thus, statistically-significant $(\mathrm{p}<0.05)$ differences between both batches for all six microbial groups investigated (aerobes, anaerobes, psychrotrophes, Enterobacteriaceae, lipolytics and proteolytics) and for two chemical indices related to microbial activity development (total volatile bases and trimethylamine) were obtained. The surface wash caused by the melting of the ice during storage and the subsequent antimicrobial effect of such acids on skin microflora of the fish can be invoked as the main reasons for the limited bacterial growth found in the corresponding mackerel muscle.

48 Running Head: Microbial inhibition in chilled mackerel.

49 Keywords: Scomber scombrus, ascorbic, citric, lactic, chilling, microbial activity. 50 
52

53 Among natural antioxidants, citric, ascorbic and lactic acids are low molecular

54 weight organic compounds that represent a relevant choice because of their easy

55 availability, low commercial cost and wide range of permitted concentrations for their

56 use in foods. Present results obtained by their inclusion in a novel icing system have led

57 to a lower microbial development in chilled mackerel when compared to its counterpart

58 fish kept under traditional icing conditions. Such a finding indicated that inclusion of

59 this acid mixture in the icing medium can lead to a marked quality and safety

60 enhancement as well as to profitable commercial value increases.

61

62 
Maintain good quality and shelf life extension of fresh fish are nowadays

66 mandatory. Flake ice has been the most employed method to cool and store fish products and partially inhibit detrimental effects on the commercial value. However, significant deterioration of sensory quality and nutritional value has been detected in chilled fish as a result of microbial and biochemical degradation mechanisms (Whittle and others 1990). To retard fish spoilage as long as possible, a wide number of preservative strategies to be combined to flake ice chilling have been tested satisfactorily such as chemical (washing or dipping by means of an aqueous solution including preservative compounds) and physical (hydrostatic high pressure, low-dose irradiation, etc.) treatments (Ashie and others 1996; Richards and others 1998) and employment of preservative packaging (Ozen and Floros 2001).

Among previous chemical treatments to chilling storage, natural low molecular weight organic acids and their sodium salts have shown to represent a relevant choice because of their easy availability, low commercial cost and wide range of permitted concentrations for their use. Thus, ascorbic and citric acids (AA and CA, respectively) are widely known for their role as chelators, acidulants in biological systems and synergists of primary antioxidants, so that a profitable effect on fish fillets (Badii and Howell 2002; Pourashouri and others 2009) and whole fish (Aubourg and others 2004) has been observed. Further, lactic acid (LA) has been reported to be effective in suppressing Gram-negative bacteria, which are known to be the most important fish spoiler group; thus, LA pre-treatment has shown to be effective in preserving and extending shelf-life in fish fillets (Kim and others 1995; Metin and others 2001), coated fish (Gogus and others 2006) and fish slices (Sallam 2007). 
Small pelagic fatty fish species can constitute food products of great economic importance in many European countries (FAO 2007a). Some of these fish species are captured in high proportions when their demand is relatively low, so that a large portion

91 of their catches is underutilized and transformed into fish meals for animals. Thus, great

92 attention is being accorded by manufacturers in the search of appropriate technological 93 treatments that may increase their shelf-life and accordingly, their trading value. One 94 such abundant species at both North Atlantic coasts is Atlantic mackerel (Scomber scombrus) belonging to the Scombridae family (FAO 2007b). Although it is recognized as a healthy food, it remains underutilized because of its short chilled shelf life (up to 910 days). Most research has been focused on the assessement of lipid hydrolysis and oxidation as these are the most relevant mechanisms of quality loss during mackerel 99 chilling storage (Decker and Hultin, 1990; Saeed and Howell, 2001). In this sense, 100 different technologies have been checked to partially inhibit them (Hwang and 101 Regenstein, 1995; Richards and others 1998). However, chilling storage of mackerel 102 has shown an important microbial activity (Jhaveri and others 1982; Bennour and others 103 1991), so that great efforts should also be directed to the inhibition of this damage 104 pathway.

The present work concerns mackerel traded as a chilled product. The study was

106 aimed to investigate the effect of including a mixture of organic acids in the icing 107 medium employed. To this end, an aqueous solution including CA, AA and LA was 108 employed as icing medium; its effect on microbial activity development was monitored 109 in mackerel muscle for up to 13 days of chilled storage. 


\section{Icing systems}

An aqueous solution containing $0.050 \%(\mathrm{w} / \mathrm{v})$ of each natural organic acid (CA,

114 AA and LA) was prepared, packed in polythene bags and kept frozen at $-20^{\circ} \mathrm{C}$ until use.

115 Traditional ice was prepared starting only from water that was packed and kept frozen

116 in the same way as the one including the organic acid mixture. Before addition to

117 individual fishes, the different ices were ground to obtain common flakes. Organic acids

118 encountered in the present research are regarded as safe (GRAS) for use in foods

119 according to European and American administrations (Madrid and others 1994; Giese 120 1996).

121 Preliminary trials were carried out in order to assess a convenient concentration

122 of the organic acid mixture used to prepare the ice. Thus, a solution combining the three 123 organic acids in the $0.005 \%$ to $0.250 \%$ concentration range was preliminary evaluated.

124 According to results obtained on the visual analysis of individual fishes, the $0.050 \%$

125 concentration was chosen as the most suitable for further investigation.

126

127 Raw fish, processing and sampling

128 Fresh mackerel (81 individuals) were caught near the Galician Atlantic coast 129 (north-western Spain) in Autumn 2010 and transported on ice to the laboratory. The 130 length and weight of the fish specimens were included in the following ranges: 21-25 $131 \mathrm{~cm}$ and 175-230 g, respectively.

132 Upon arrival in the laboratory, nine individual fishes were separated and 133 analyzed as starting raw fish (day 0); for it, three different groups (three individuals per 134 group) were analyzed independently in order to achieve the statistical analysis $(n=3)$.

135 The remaining fish were divided into two batches (36 individuals in each batch). The 
136 first batch (preserved fish; P batch) was placed in boxes and directly surrounded by ice 137 prepared with the organic acid-mixture above mentioned. Fish corresponding to the 138 second batch (control batch; $\mathrm{C}$ batch) was placed in boxes and surrounded by traditional 139 ice prepared with water.

140 In both batches, a 1:1 fish-to-ice ratio was employed. Both batches were placed

141 in a refrigerated room $\left(4^{\circ} \mathrm{C}\right)$. Boxes employed allowed draining and ice was renewed 142 when required. Fish samples from the two different batches were taken for analysis on 143 days 3, 6, 10 and 13. At each sampling time, nine individuals of each batch were taken 144 for analysis, being considered into three groups (three individuals in each group) that 145 were studied independently in order to achieve the statistical analysis $(n=3)$.

\section{$147 \quad$ Microbial analysis}

148 Samples of $10 \mathrm{~g}$ of fish muscle were dissected aseptically from chilled fish 149 specimens, mixed with $90 \mathrm{ml}$ of $0.1 \%$ peptone water (Merck, Darmstadt, Germany), and 150 homogenized in sterilized stomacher bags (AES, Combourg, France) as previously 151 described (Ben-Gigirey and others 1998; Ben-Gigirey and others 1999). In all cases, 152 serial dilutions from the microbial extracts were prepared in $0.1 \%$ peptone water.

153 Total aerobes were investigated by surface inoculation on plate count agar 154 (PCA, Oxoid Ltd., London, UK), after incubation at $30^{\circ} \mathrm{C}$ for $48 \mathrm{~h}$. Psychrotrophes were 155 also investigated in PCA but incubation was carried out at $7-8{ }^{\circ} \mathrm{C}$ for 7 days. 156 Enterobacteriaceae were investigated by pour plating using Violet Red Bile Agar 157 (VRBA) (Merck, Darmstadt, Germany) after incubation at $37{ }^{\circ} \mathrm{C}$ for $24 \mathrm{~h}$. 158 Microorganisms exhibiting a proteolytic or lipolytic phenotype were investigated in 159 casein-agar medium or tributyrin-agar, respectively, after incubation at $30{ }^{\circ} \mathrm{C}$ for $48 \mathrm{~h}$, 160 as previously described by Ben-Gigirey and others (2000). 

undergoing statistical analysis. All analyses were done by triplicate.

163

\section{Chemical analysis of microbial activity}

Total volatile base-nitrogen (TVB-N) values were measured as previously reported (Aubourg and others 1997). Briefly, fish muscle (10 g) was extracted with 6\% perchloric acid $(30 \mathrm{ml})$ and brought up to $50 \mathrm{ml}$. An aliquot of the acid extracts was rendered alkaline to $\mathrm{pH} 13$ with $20 \% \mathrm{NaOH}$ and then steam-distillated. Finally, the TVB-N content was determined by titration of the distillate with $10 \mathrm{mM} \mathrm{HCl}$. Results were expressed as mg TVB-N/ $100 \mathrm{~g}$ muscle.

Trimethylamine-nitrogen (TMA-N) values were determined by the picrate method, as previously described by Tozawa and others (1971). This involves the preparation of a 5\% trichloroacetic acid extract of fish muscle (10 g / $25 \mathrm{ml})$. Results were expressed as mg TMA-N/ 100 g muscle.

\section{$\underline{\text { Statistical analysis }}$}

Data obtained from the different microbial and chemical analyses were subjected to the ANOVA method $(\mathrm{p}<0.05)$ to explore differences by two different ways: icing conditions effect and chilling time effect. For it, the PASW Statistics 18 software for Windows (SPSS Inc., Chicago, IL, USA) was employed. The comparison of means was

181 performed using the least-squares difference (LSD) method. Correlation analysis among 182 parameters (chilling time, microbial indices and chemical values) was carried out by 183 means of the Pearson correlation coefficient (r value). 


\section{Microbial count analysis}

The development of aerobic bacteria was significantly $(\mathrm{p}<0.05)$ slowed down in the batch submitted to the organic acid-icing system, as compared to the control batch (Table 1). Thus, the differences in the microbial numbers reached its maximum, more than two log units, at day 6 of storage, while the average difference for aerobic mesophiles throughout storage was 1.18 log units. Remarkably, the control batch stored in traditional ice for 13 days reached levels above $10^{7} \mathrm{CFU} / \mathrm{g}$. Bennour and others (1991) and Gram and Huss (1996) reported aerobe count to be the breakpoint for relevant microbial spoilage (Gram and Huss 1996). On contrast, the aerobe counts in the batch preserved with organic acids were round $10^{6} \mathrm{CFU} / \mathrm{g}$ at that time (Table 1).

196 Aerobe counts as high as $10^{7} \mathrm{CFU} / \mathrm{g}$ have been reported in the skin of horse mackerel stored for 7 days at $4^{\circ} \mathrm{C}$ (Kuda and others 1996). This result is quite in agreement with our results and that underscores the microbial inhibition exerted by the organic acidicing system. In the present research, both fish batches showed fair correlation values

200 between aerobe counts and chilling time ( $\mathrm{r}=0.93$ and 0.84 for C- and P-fish, 201 respectively; Table 2).

With respect to the development of anaerobic bacteria, significant $(\mathrm{p}<0.05)$ advantages derived from the use of the organic acid-icing system were also observed (Table 1). Thus, the average differences between batches $\mathrm{C}$ and $\mathrm{P}$ in the anaerobic counts throughout storage were higher than 2 log units, which means that the slowing down of anaerobic bacterial growth was over 99\%. Furthermore, final counts after 13 days of storage differed in more than 3.60 log units, which clearly indicates a remarkably better control of anaerobes growth as a result of the storage in the organic 
acid-icing system. Correlation value between aerobe counts and chilling time was only

210 good in the case of the C batch ( $r=0.93$; Table 2).

212 differences among batches after 10 days of storage (Table 1). The development of this 213 microbial group was quite limited in both batches on early storage periods, with

214 microbial numbers below $4.85 \log$ CFU/g units until day six, although the organic acid

215 icing system provided a remarkable protective effect. Differences between batches increased on day 10, with the psychrotrophes higher than $7 \log$ units on the control batch while the organic acid icing system exhibited values below 6 log units. Even a more significant effect was observed on day 13, although both batches were above the 6 $\log$ CFU/g units breakpoint of microbial spoilage. The average differences between batches during the whole storage period rose to 1.17 log units, this indicating a remarkable slowing down of the growth of this bacterial group in the organic acid-icing system. Moreover, as storage progressed higher differences in the psychrotrophe counts were achieved, these reaching its maximum at day 13; at this time (day 13), a difference of $1.50 \log$ units between batches was observed. As in the case of the aerobes, the psychrotrophes did not reach $10^{7} \mathrm{CFU} / \mathrm{g}$ in the muscle of the fish specimens stored in the organic acid-icing system, while this value was clearly surpassed in the control batch. Both fish batches showed good correlation values between psychrotrophe counts and chilling time ( $\mathrm{r}=0.94$ and 0.93 for $\mathrm{C}$ - and P-fish, respectively; Table 2), according to previous research on chilled mackerel (Bennour and others 1991). batches until day 10 (Table 3). These results confirm the very good initial quality of the mackerel specimens employed and the limited growth of enteric bacteria during chilled 
234 had also been reported before by other authors for related fish species such as horse

235 mackerel (Rodríguez and others 2005) or jack mackerel (Figueroa and others 1990),

236 subjected to storage on flake ice and slurry ice conditions. However, in our study, the

237 counts for this bacterial group were similar in the organic acid-icing system than in the

238 control batch except for advanced storage times (day 13), where a difference of $1.95 \log$

239 units between batches was determined. However, the fact that the counts for this

240 bacterial group were quite low up to day 10 (below $1.30 \log$ CFU/ g) and as a result of

241 the ample standard deviation values obtained, no conclusion could be depicted related to

242 any beneficial effect of the organic acid system up to day 10 . The results also indicate a

243 good control of this microbial group up to day 10 in both batches, this being probably

244 related with the good hygienic practices and the rapid chilling of fish. However, on day

24510 the microbial quality of the fish was at its limit, this leading to a rapid increase in the

246 numbers of Enterobacteriaceae at day 13. According to this Enterobacteriaceae count

247 distribution, fair correlation values with chilling time were only obtained for fish

248 corresponding to the $\mathrm{P}$ batch $(\mathrm{r}=0.87$; Table 2$)$.

249 This work was also aimed at evaluating the effect of the organic acid-mixture on

250 microbial groups exhibiting specific spoilage phenotypes. Thus, the development of

251 bacteria able to produce extracellular lipolytic enzymes has been described to negatively

252 affect the preservation of medium-fat fish species (Rodríguez and others 2005).

253 Likewise, the inhibition of proteolytic bacteria, able to synthesize and secrete

254 proteolytic enzymes, has also been linked to a better preservation of fish species, due to

255 the limitation of the physical damage of the muscle structure also reducing the

256 formation of alkaline compounds such as ammonia and related metabolites (Venugopal

257 1990; Odagami and others 1994; Makarios-Laham and Lee 1993; Rodríguez and others

258 2003). Accordingly, the inhibition of bacteria exhibiting lipolytic and/or proteolytic 
phenotypes may limit the negative effects of lipases and proteases on the quality of fish

260 species, since these enzymes have always been characterized for retaining activity during long storage periods even under refrigeration temperatures (Alford and Pierce 1961).

With respect to the lipolytic bacteria, and as in the cases of other microbial 264 groups studied before, significant $(\mathrm{p}<0.05)$ differences were determined between 265 batches (Table 3). Thus, the average difference during storage was 1.41 log units, and reached its maximum at advanced stages of storage. Remarkably, differences of 1.25 and $2.73 \log$ units were determined at 10 and 13 days of storage, respectively. According to these results, the growth of bacteria potentially involved in the lipolytic breakdown of mackerel was slowed down as a consequence of storage in the organic acid-icing system. Similar inhibition of lipolytic microorganisms was observed with other preservation methods such as ice slurries for other medium-fat and fat fish species like horse mackerel (Rodríguez and others 2005) and sardine (Campos and others 2005), respectively. Good correlation values between lipolytic counts and chilling time were only obtained for fish corresponding to the $\mathrm{C}$ batch $(\mathrm{r}=0.93$; Table 2). With respect to the proteolytic bacteria, a similar type of behavior was observed than in the case of lipolytic ones (Table 3). Thus, the counts of proteolytic bacteria in mackerel muscle stored in the organic acid-icing system did not reach levels of $10^{4}$ $\mathrm{CFU} / \mathrm{g}$ at any storage time, while the control batch exhibited values higher than $10^{5}$ 279 CFU/g after 10 days of storage. The average difference in the counts between batches 280 throughout storage was $1.19 \log$ units, and the growth inhibition was more intense as storage progressed, a result that is in agreement with those observed for the majority of the microbial groups studied before. As with lipolytic counts, proteolytic ones only 
provided fair correlation values with chilling time in the case of the $\mathrm{C}$ batch $(\mathrm{r}=0.89$;

Table 2).

A marked inhibitory effect of the novel icing system on several microbial groups

286 investigated was observed, this being especially remarkable in the cases of the aerobes, anaerobes and lipolytic bacteria. The surface wash caused by the melting of the ice during storage and the subsequent antimicrobial effect of the organic acids on skin microflora of the fish can be invoked as the main reasons for the limited bacterial growth found in the corresponding mackerel muscle. Similar results had been reported before for other preservation methods such as ice slurries, where ice melting led to the release of salt that exerted a bacteriostatic effect on fish microflora (Rodríguez and others 2003; Rodríguez and others 2005; Campos and others 2005). Moreover, previous studies on horse mackerel have confirmed the presence of Proteus penneri and Staphylococcus xylosus strains exhibiting remarkable lipolytic and proteolytic phenotype, and, to a lesser extent, Proteus vulgaris. The fact that the organic acid-icing system evaluated in this study significantly $(\mathrm{p}<0.05)$ slowed down the growth of proteolytic and lipolytic bacteria in mackerel muscle, stresses the benefits that such storage system may have on the maintenance of the quality of this fish species.

\section{Chemical analysis of microbial activity}

Microbial activity development was also measured by chemical indices. The TVB-N content showed a relatively high value (30.21 \pm 1.48$)$ for starting fish (Table 4); this value is found quite similar to the one obtained by Civera and others (1993) (31.9 mg/ 100 g muscle) but markedly higher than the values reported by Bennour and others (1991) and Fagan and others (2003). In this study (Table 4), a higher $(\mathrm{p}<0.05)$ TVB-N content in fish samples corresponding to the control batch could be observed when 
compared to preserved fish in the 6-13-day period. Volatile amine content showed a

309 marked increase in the 10-13-day period for C-fish, this being in agreement with a

310 previous report on chilled mackerel (Bennour and others 1991); in the case of the P-

311 batch, a marked increase on volatile amine formation was only attained at the end of the

312 experiment. As for aerobe count assessment, TVB-N values showed a mean value

313 decrease in the P-fish batch in the 0-6-day period; this result can be explained as a result

314 of the preservative effect of the organic acid presence in the ice and by a relatively low

315 microbial activity at that period. Good correlation values between TVB-N content and

316 chilling time were obtained for fish corresponding to the $\mathrm{C}$ batch $(r=0.91$; Table 2$)$,

317 according to the strong relationship between TVB-N content and freshness loss (Whittle

318 and others 1990; Bennour and others 1991). Volatile amine compounds have been

319 reported to be produced partially by means of endogenous enzyme activity, but mostly as a result of microbial development (Whittle and others 1990).

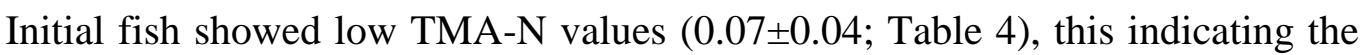

high freshness of the raw material employed. All fish specimens showed a progressive TMA-N content increase $(\mathrm{p}<0.05)$ with time regardless the icing system employed; such increase was specially marked at the end of storage, this also being in agreement with previous reports on chilled mackerel (Jhaveri and others 1982; Bennour and others 1991). As a result of this, good correlation values between TMA-N values and chilling time were observed ( $r=0.93$ and 0.95 , for C- and P-fish, respectively; Table 2). Such results are in agreement with previous research where TMA-N assessment showed to be an accurate index for assessing quality loss during mackerel chilling storage (Bennour and others 1991; Civera and others 1993), according to the strong relationship between TMA-N content and freshness loss (Whittle and other 1990). As for TVB-N value,

332 trimethylamine has been reported to be produced mostly as a result of microbial 
333 development. Comparison between both kinds of icing conditions (Table 4) showed

334 lower TMA-N mean values throughout the whole experiment as a result of employing

335 the organic acid-mixture in the icing medium; such differences were found significant at

336 the end of the experiment.

337 Relationship between chemical and microbial parameters was also analyzed in

338 the present research (Table 5). Related to the control batch, better correlation values 339 with microbial count assessments were obtained for TMA-N values $(r=0.84-0.92)$ than

340 for TVB-N scores $(r=0.78-0.89)$. In this sense, previous research (Bennour and others

341 1991) showed that TMA-N content was profitable in order to classify the freshness

342 degree of chilled mackerel (first, second and third grade would correspond to 0-1, 1-3

343 and 3-6 mg TMA-N/ 100 g muscle, respectively). In addition, a previous correlation

344 study between TVB-N and TMA-N values and sensory acceptance in chilled mackerel

345 concluded that this species was not suitable for consumption when both parameters

346 were above 40 and $4 \mathrm{mg} / 100 \mathrm{~g}$ muscle, respectively (Civera and others 1993). In the

347 present research, a higher TVB-N value was attained in the case of the control fish at

348 the end of the experiment (Table 4).

349 Related to the preserved batch, correlation values were again better for TMA-N 350 value than for TVB-N scores. For both chemical parameters, fair correlation values were obtained with aerobes, psychrotrophes and Enterobacteriaceae.

\section{CONCLUSIONS}

The results obtained in this study indicated significant $(\mathrm{p}<0.05)$ differences between batches for all six microbial groups investigated, as well as in both chemical indices related to microbial activity development. These findings clearly indicated a significantly $(\mathrm{p}<0.05)$ lower bacterial growth in mackerel muscle subjected to storage in 
358 the organic acid-icing system as compared with traditional flake ice. The novel icing 359 system evaluated in this work contains three organic acids, all of them previously 360 reported as possessing antimicrobial and antioxidant activities. In addition, such natural

361 organic acids are known to represent a relevant choice because of their easy availability,

362 low commercial cost and wide range of permitted concentration for their use in foods.

363 As being a highly fatty fish species, previous research on quality loss of chilled 364 mackerel has mostly focused the lipid changes, these concerning specially lipid 365 oxidation and hydrolysis. In the present investigation, an extensive study on microbial 366 activity development during the chilled storage of this pelagic fish species has been 367 undertaken; as a result, progress of different bacteria groups has been described, as well 368 as its relationship with chemical parameters related to microbial activity development.

\section{ACKNOWLEDGEMENTS}

The authors thank Mr. Marcos Trigo and Mrs. Cristina Nine for their excellent

373 technical assistance. This work was supported by the Secretaría Xeral de I+D from the

374 Xunta de Galicia (Galicia, Spain) through the Research Project PGIDIT 10 TAL 402001 375 PR. 
378 Alford JA, Pierce DA. 1961. Lipolytic activity of microorganisms at low and intermediate temperatures. III. Activity of microbial lipases at temperatures below $0^{\circ} \mathrm{C}$. J Food Sci 26:518.

Ashie I, Smith J, Simpson B. 1996. Spoilage and shelf-life extension of fresh fish and shellfish. Crit Rev Food Sci Nutr 36:87-121.

Aubourg S, Pérez-Alonso F, Gallardo J. 2004. Studies on rancidity inhibition in frozen horse mackerel (Trachurus trachurus) by citric and ascorbic acids. Eur J Lipid Sci Technol 106:232-240.

Aubourg S, Sotelo C, Gallardo JM. 1997. Quality assessment of sardines during storage by measurement of fluorescent compounds. J Food Sci 62:295-298, 304.

Badii F, Howell N. 2002. Effect of antioxidants, citrate, and cryoprotectants on protein denaturation and texture of frozen cod (Gadus morhua). J Agric Food Chem 50:2053-2061. muscle during frozen storage. J Food Prot 61:608-615.

Ben-Gigirey B, Vieites Baptista de Sousa J, Villa T, Barros-Velázquez J. 1999. Histamine and cadaverine production by bacteria isolated from fresh and frozen

Ben-Gigirey B, Vieites Baptista de Sousa J, Villa T, Barros-Velázquez J. 1998. Changes in biogenic amines and microbiological analysis in albacore (Thunnus alalunga) albacore (Thunnus alalunga). J Food Prot 62:933-939.

Ben-Gigirey B, Vieites Baptista de Sousa J, Villa T, Barros-Velázquez J. 2000. Characterization of biogenic amine-producing Stenotrophomonas maltophilia strains isolated from white muscle of fresh and frozen albacore tuna. Int J Food Microb 57:19-31. 
Bennour M, El Marrakchi A, Bouchriti N, Hamama A, El Ouadaa M. 1991. Chemical and microbiological assessment of mackerel (Scomber scombrus) stored in ice. J Food Prot 784:789-792.

Campos C, Rodríguez O, Losada V, Aubourg S, Barros-Velázquez J. 2005. Effects of storage in ozonised slurry ice on the sensory and microbial quality of sardine (Sardina pilchardus). Int J Food Microb 103:121-130.

Civera T, Turi R, Bisio C, Parisi E, Fazio G. 1993. Sensory and chemical assessment of marine teleosteans. Relationship between total volatile basic nitrogen, trimethylamine and sensory characteristics. Sci Alim 13:109-117.

Decker E, Hultin H. 1990. Factors influencing catalysis of lipid oxidation by the soluble fraction of mackerel muscle. J Food Sci 55:947-950, 953.

Fagan J, Gormley R, Mhuircheartaigh M. 2003. Effect of freeze-chilling, in comparison with fresh, chilling and freezing, on some quality parameters of raw whiting, mackerel, and salmon portions. Lebensm Wissen Technol36:647-655.

[FAO] Food and Agriculture Organization. 2007a. Fishery statistics. Commodities. Yearbook 2005. Vol. 101. Rome, Italy: FAO United Nations. p 134-178.

[FAO] Food and Agriculture Organization. 2007b. Fishery statistics. Capture production. Yearbook 2005. Vol. 100/1. Rome, Italy: FAO United Nations. p 262.

Figueroa G, Galeno H, Troncoso M, Aguilera JM. 1990. Analysis of the microbial flora of jack mackerel (Trachurus murphyi) minced products. Sci Alim 10:907-912.

Giese J. 1996. Antioxidants: Tools for preventing lipid oxidation. Food Technol 50:7380. 
424 Gogus U, Bozoglu F, Yurdugul S. 2006. Comparative effects of lactic acid, nisin, coating combined and alone applications on some postmortem quality criteria of refrigerated Sardina pilchardus. J Food Qual 29:658-671.

Gram L, Huss H. 1996. Microbiological spoilage of fish and fish products. Int J Food Microb 33:121-137.

Hwang K, Regenstein J. 1995. Hydrolysis and oxidation of mackerel (Scomber scombrus) mince lipids with $\mathrm{NaOCl}$ and $\mathrm{NaF}$ treatments. J Aquat Food Prod Technol 4:19-30.

Jhaveri S, Leu S, Constantinides S. 1982. Atlantic mackerel (Scomber scombrus, L.): Shelf life in ice. J Food Sci 47:1808-1810.

Kim C, Hearnsberger J, Eun J. 1995. Gram-negative bacteria in refrigerated catfish fillets treated with lactic culture and lactic acid. J Food Prot 58:639-643.

Kuda T, Matsumoto C, Yano T. 1996. Changes in acid and alkaline phosphatase 437 activities during the spoilage of raw muscle from horse mackerel (Trachurus japonicus) and gurnard (Lepidotriga microptera). Food Chem 76:443-447.

Madrid A, Madrid J, Madrid R. 1994. Chilling, freezing and ultra-freezing of fish and derivates. In: Madrid A, editor. Technology of fish and its derivatives. Madrid,

Makarios-Laham IK, Lee TC. 1993. Protein hydrolysis and quality deterioration of refrigerated and frozen seafood due to obligately psychrophilic bacteria. J Food Sci, 58:310-313.

Metin S, Erkan N, Varlik C, Aran N. 2001. Extension of shelf life of chub mackerel 446 (Scomber japonicus Houttuyn 1780) treated with lactic acid. Eur Food Res Technol 213:174-177. 
Odagami T, Morita J, Takama K, Suzuki S. 1994. Substrate specificities of extracellular proteases produced by marine putrefactive bacteria, Shewanella putrefaciens and Alteromonas haloplanktis. Lett Appl Microb 18:50-52.

Ozen B, Floros J. 2001. Effects of emerging food processing techniques on the packaging materials. Trends Food Sci Technol 12:60-67.

Pourashouri P, Shabanpour B, Aubourg S, Daghigh Rohi J, Shabani, A. 2009. An investigation of rancidity inhibition during storage of Wels catfish (Silurus glanis) fillets by previous ascorbic and citric acid treatment. Int J Food Sci Technol 44:1503-1509.

Richards M, Kelleher S, Hultin H. 1998. Effect of washing with or without antioxidants on quality retention of mackerel fillets during refrigerated and frozen storage. $\mathrm{J}$

Rodríguez O, Aubourg S, Piñeiro C, Barros-Velázquez J. 2003. Evaluation of sensory 461 and microbiological changes and identification of proteolytic bacteria during the iced storage of farmed turbot (Psetta maxima). J Food Sci 68:2764-2771.

Rodríguez O, Losada V, Aubourg S, Barros-Velázquez J. 2005. Sensory, microbial and chemical effects of a slurry ice system on horse mackerel (Trachurus trachurus). J Sci Food Agric 85:235-242 .

Saeed S, Howell N. 2001. 12-lipoxygenase activity in the muscle tissue of Atlantic mackerel (Scomber scombrus) and its prevention by antioxidants. J Sci Food Agric 81:745-750.

Sallam KI. 2007. Antimicrobial and antioxidant effects of sodium acetate, sodium 470 lactate, and sodium citrate in refrigerated sliced salmon. Food Cont 18:566-575. 
471 Tozawa H, Erokibara K, Amano K. 1971. Proposed modification of Dyer's method for

472 trimethylamine determination in codfish. In: Kreuzer R, editor. Fish Inspection 473 and Quality Control. London, UK: Fishing News Books Ltd. p 187-190.

474 Venugopal V. 1990. Extracellular proteases of contaminant bacteria in fish spoilage: A $475 \quad$ review. J Food Prot 53:341-350.

476 Whittle K, Hardy R, Hobbs G. 1990. Chilled fish and fishery products. In: Gormley T, 477 editor. Chilled foods: The state of the art. New York, USA: Elsevier Applied 478 Science. p 87-116.

479

480

481 


\section{TABLE 1}

Aerobe, anaerobe and psychrotrophe count (log CFU/ g muscle) assessment* in chilled mackerel kept under different icing conditions**

\begin{tabular}{ccccccc}
\hline $\begin{array}{c}\text { Chilling } \\
\text { Time } \\
\text { (days) }\end{array}$ & \multicolumn{2}{c}{ Aerobes } & \multicolumn{2}{c}{ Anaerobes } & \multicolumn{2}{c}{ Psychrotrophes } \\
\cline { 2 - 7 } & $\mathbf{C}$ & $\mathbf{P}$ & $\mathbf{C}$ & $\mathbf{P}$ & $\mathbf{C}$ & $\mathbf{P}$ \\
\hline Raw fish & $3.31 \mathrm{C}$ & $3.31 \mathrm{~B}$ & $1.97 \mathrm{D}$ & $1.97 \mathrm{AB}$ & $3.26 \mathrm{C}$ & $3.26 \mathrm{~B}$ \\
& $(0.08)$ & $(0.08)$ & $(0.85)$ & $(0.85)$ & $(0.37)$ & $(0.37)$ \\
\hline 3 & $3.41 \mathrm{BC}$ & $3.12 \mathrm{~B}$ & $3.33 \mathrm{C}$ & $2.79 \mathrm{~A}$ & $4.02 \mathrm{BC}$ & $3.16 \mathrm{~B}$ \\
& $(0.65)$ & $(0.19)$ & $(0.60)$ & $(0.70)$ & $(0.61)$ & $(1.02)$ \\
\hline 6 & $4.21 \mathrm{aB}$ & $2.20 \mathrm{bC}$ & $3.50 \mathrm{aC}$ & $1.99 \mathrm{bB}$ & $4.85 \mathrm{~B}$ & $3.77 \mathrm{~B}$ \\
& $(0.37)$ & $(0.17)$ & $(0.41)$ & $(0.05)$ & $(0.30)$ & $(1.06)$ \\
\hline 10 & $6.44 \mathrm{aA}$ & $5.34 \mathrm{bA}$ & $4.57 \mathrm{aB}$ & $1.99 \mathrm{bB}$ & $7.06 \mathrm{aA}$ & $5.74 \mathrm{bA}$ \\
& $(0.45)$ & $(0.52)$ & $(0.43)$ & $(0.05)$ & $(0.37)$ & $(0.45)$ \\
\hline 13 & $7.28 \mathrm{aA}$ & $6.05 \mathrm{bA}$ & $5.68 \mathrm{aA}$ & $1.99 \mathrm{bB}$ & $7.93 \mathrm{aA}$ & $6.43 \mathrm{bA}$ \\
& $(0.32)$ & $(0.77)$ & $(0.44)$ & $(0.05)$ & $(0.50)$ & $(0.51)$ \\
\hline
\end{tabular}

* Mean values of three replicates $(n=3)$; standard deviations are indicated in brackets.

For each parameter and for each chilling time, mean values followed by different low-case letters $(a, b)$ indicate significant $(p<0.05)$ differences as a result of the icing condition. For each parameter and for each icing condition, values followed by different capital letters (A-D) denote significant $(\mathrm{p}<0.05)$ differences as a result of the chilling time. No letters are indicated when significant differences are not found $(\mathrm{p}>0.05)$.

** Abbreviations of icing conditions: $\mathrm{P}$ (ice including the organic acid-mixture) and $\mathrm{C}$ (ice prepared only from water). 


\section{TABLE 2}

Correlation coefficient ( $r$ value)* between the chilled storage time and the different parameters analyzed in chilled mackerel kept under different icing conditions**

\begin{tabular}{ccc}
\hline \multirow{2}{*}{ Quality parameter } & \multicolumn{2}{c}{ r value } \\
\cline { 2 - 3 } & $\mathbf{C}$ & $\mathbf{P}$ \\
\hline Aerobes & $0.93^{\mathrm{b}}$ & $0.84^{\mathrm{b}}$ \\
\hline Anaerobes & $0.93^{\mathrm{a}}$ & $-0.39^{\mathrm{b}}$ \\
\hline Psychrotrophes & $0.94^{\mathrm{a}}$ & $0.93^{\mathrm{b}}$ \\
\hline Enterobacteriaceae & $0.79^{\mathrm{b}}$ & $0.87^{\mathrm{b}}$ \\
\hline Lipolytics & $0.93^{\mathrm{b}}$ & $0.80^{\mathrm{b}}$ \\
\hline Proteolytics & $0.89^{\mathrm{a}}$ & $0.69^{\mathrm{c}}$ \\
\hline Total volatile base-nitrogen & $0.91^{\mathrm{b}}$ & $0.79^{\mathrm{b}}$ \\
\hline Trimethylamine-nitrogen & $0.93^{\mathrm{b}}$ & $0.95^{\mathrm{b}}$ \\
\hline
\end{tabular}

* For each index, linear ${ }^{\mathrm{a}}$, quadratic ${ }^{\mathrm{b}}$ and logarithmic ${ }^{\mathrm{c}}$ fittings were studied. In each case, the best correlation coefficient value is expressed.

** Abbreviations of icing conditions as expressed in Table 1. 


\section{TABLE 3}

Enterobacteriaeceae, lipolytic and proteolytic count (log CFU/g muscle) assessment* in chilled mackerel kept under different icing conditions**

\begin{tabular}{ccccccc}
\hline $\begin{array}{c}\text { Chilling } \\
\text { Time } \\
\text { (days) }\end{array}$ & \multicolumn{2}{c}{ Enterobacteriaceae } & \multicolumn{2}{c}{ Lipolytics } & \multicolumn{2}{c}{ Proteolytics } \\
\cline { 2 - 7 } & $\mathbf{C}$ & $\mathbf{P}$ & $\mathbf{C}$ & $\mathbf{P}$ & $\mathbf{C}$ & $\mathbf{P}$ \\
\hline Raw fish & $0.99 \mathrm{~B}$ & $0.99 \mathrm{~B}$ & $2.16 \mathrm{D}$ & $2.16 \mathrm{AB}$ & $2.09 \mathrm{C}$ & $2.09 \mathrm{~B}$ \\
& $(0.01)$ & $(0.01)$ & $(0.28)$ & $(0.28)$ & $(0.18)$ & $(0.18)$ \\
\hline 3 & $0.99 \mathrm{~B}$ & $0.99 \mathrm{~B}$ & $3.32 \mathrm{C}$ & $2.85 \mathrm{~A}$ & $3.51 \mathrm{~B}$ & $3.16 \mathrm{AB}$ \\
& $(0.05)$ & $(0.05)$ & $(0.56)$ & $(0.41)$ & $(0.11)$ & $(1.01)$ \\
\hline 6 & $0.99 \mathrm{~B}$ & $1.23 \mathrm{AB}$ & $3.30 \mathrm{aC}$ & $2.10 \mathrm{bB}$ & $3.10 \mathrm{~B}$ & $2.76 \mathrm{AB}$ \\
& $(0.05)$ & $(0.41)$ & $(0.52)$ & $(0.18)$ & $(0.35)$ & $(0.69)$ \\
\hline 10 & $0.99 \mathrm{~B}$ & $1.29 \mathrm{AB}$ & $4.81 \mathrm{aB}$ & $3.56 \mathrm{bAB}$ & $5.30 \mathrm{aA}$ & $3.78 \mathrm{bA}$ \\
& $(0.05)$ & $(0.53)$ & $(0.07)$ & $(1.15)$ & $(0.29)$ & $(1.09)$ \\
\hline 13 & $4.42 \mathrm{aA}$ & $2.47 \mathrm{bA}$ & $6.40 \mathrm{aA}$ & $3.67 \mathrm{bAB}$ & $5.51 \mathrm{aA}$ & $2.96 \mathrm{bAB}$ \\
& $(0.44)$ & $(0.93)$ & $(0.20)$ & $(1.85)$ & $(0.52)$ & $(1.48)$ \\
\hline
\end{tabular}

* Mean values of three replicates $(n=3)$; standard deviations are indicated in brackets.

For each parameter and for each chilling time, mean values followed by different low-case letters $(a, b)$ indicate significant $(p<0.05)$ differences as a result of the icing condition. For each parameter and for each icing condition, values followed by different capital letters (A-D) denote significant $(\mathrm{p}<0.05)$ differences as a result of the chilling time. No letters are indicated when significant differences are not found ( $\mathrm{p}>0.05)$.

** Abbreviations of icing conditions as expressed in Table 1. 


\section{TABLE 4}

Evolution of total volatile base-nitrogen (TVB-N) and trimethylamine-nitrogen (TMA-N) values* in chilled mackerel kept under different icing conditions**

\begin{tabular}{ccccc}
\hline $\begin{array}{c}\text { Chilling Time } \\
\text { (days) }\end{array}$ & \multicolumn{2}{c}{ TVB-N (mg/ $\mathbf{1 0 0}$ g muscle) } & \multicolumn{2}{c}{ TMA-N (mg/ $\mathbf{1 0 0}$ g muscle) } \\
\cline { 2 - 5 } Raw fish & $\mathbf{C}$ & $\mathbf{P}$ & $\mathbf{C}$ & $\mathbf{P}$ \\
& $30.21 \mathrm{C}$ & $30.21 \mathrm{~B}$ & $0.07 \mathrm{D}$ & $0.07 \mathrm{D}$ \\
& $(1.48)$ & $(1.48)$ & $(0.04)$ & $(0.04)$ \\
\hline 3 & $30.74 \mathrm{C}$ & $28.69 \mathrm{BC}$ & $0.29 \mathrm{CD}$ & $0.16 \mathrm{D}$ \\
& $(2.00)$ & $(1.70)$ & $(0.20)$ & $(0.04)$ \\
\hline 6 & $30.15 \mathrm{aC}$ & $27.44 \mathrm{bC}$ & $0.54 \mathrm{C}$ & $0.34 \mathrm{C}$ \\
& $(1.57)$ & $(0.62)$ & $(0.27)$ & $(0.06)$ \\
\hline 10 & $35.12 \mathrm{aB}$ & $30.47 \mathrm{bB}$ & $1.04 \mathrm{~B}$ & $0.85 \mathrm{~B}$ \\
& $(2.08)$ & $(1.57)$ & $(0.12)$ & $(0.14)$ \\
\hline 13 & $44.61 \mathrm{aA}$ & $35.21 \mathrm{bA}$ & $2.32 \mathrm{aA}$ & $1.47 \mathrm{bA}$ \\
& $(1.76)$ & $(2.53)$ & $(0.25)$ & $(0.23)$ \\
\hline
\end{tabular}

* Mean values of three replicates $(n=3)$; standard deviations are indicated in brackets.

For each parameter and for each chilling time, mean values followed by different low-case letters indicate significant $(\mathrm{p}<0.05)$ differences as a result of the icing condition. For each parameter and for each icing condition, values followed by different capital letters $(A-D)$ denote significant $(\mathrm{p}<0.05)$ differences as a result of the chilling time. No letters are indicated when significant differences are not found ( $\mathrm{p}>0.05)$.

** Abbreviations of icing conditions as expressed in Table 1. 


\section{TABLE 5}

Linear correlation coefficient values between microbial and chemical parameters analyzed in chilled mackerel kept under different icing conditions*

\begin{tabular}{ccccc}
\hline \multirow{2}{*}{ Microbial parameter } & \multicolumn{2}{c}{ Total volatile base-nitrogen } & \multicolumn{2}{c}{ Trimethylamine-nitrogen } \\
\cline { 2 - 5 } & $\mathbf{C}$ & $\mathbf{P}$ & $\mathbf{C}$ & $\mathbf{P}$ \\
\hline Aerobes & 0.86 & 0.84 & 0.88 & 0.84 \\
\hline Anaerobes & 0.84 & -0.30 & 0.84 & -0.37 \\
\hline Psychrotrophes & 0.84 & 0.75 & 0.88 & 0.92 \\
\hline Enterobacteriaceae & 0.89 & 0.84 & 0.87 & 0.88 \\
\hline Lipolytics & 0.89 & 0.68 & 0.92 & 0.80 \\
\hline Proteolytics & 0.78 & 0.07 & 0.88 & 0.42 \\
\hline
\end{tabular}

* Abbreviations of icing conditions as expressed in Table 1. 